\title{
Mesoporous Silica SBA-16 Functionalized with Alkoxysilane Groups: Preparation, Characterization, and Release Profile Study
}

\author{
Gracielle Ferreira Andrade, ${ }^{1}$ Daniel Cristian Ferreira Soares, ${ }^{1}$ \\ Ramon Kenned de Sousa Almeida, ${ }^{2}$ and Edésia Martins Barros Sousa ${ }^{1}$ \\ ${ }^{1}$ Laboratório de Materiais Nanoestruturados para Bioaplicações, Centro de Desenvolvimento da Tecnologia Nuclear, \\ Av. Antônio Carlos 6.627, Pampulha, 31270-901 Belo Horizonte, MG, Brazil \\ ${ }^{2}$ Universidade Estadual de Campinas_Instituto de Quimica, Cidade Universitária Zeferino Vaz Distrito de Barão Geraldo, \\ 13083-970 Campinas, SP, Brazil
}

Correspondence should be addressed to Edésia Martins Barros Sousa, sousaem@cdtn.br

Received 8 March 2012; Accepted 22 May 2012

Academic Editor: Anukorn Phuruangrat

Copyright (C) 2012 Gracielle Ferreira de Andrade et al. This is an open access article distributed under the Creative Commons Attribution License, which permits unrestricted use, distribution, and reproduction in any medium, provided the original work is properly cited.

\begin{abstract}
A mesoporous material sphere based on silica, SBA-16, was chemically modified with alkoxysilane using two different solvents: methanol and toluene. The influence of the chemical modification of the matrix on the release rate of a model drug was also studied. The structural characteristics of the materials were evaluated by small-angle X-ray diffraction, $\mathrm{N}_{2}$ adsorption, and transmission electron microscopy. The functionalization of the matrix was evaluated using thermal analysis, FTIR spectroscopy, ${ }^{13} \mathrm{C}$ and ${ }^{29} \mathrm{Si}$ solid-state nuclear magnetic resonance, and elemental analysis, CHN. The results show that alkoxysilane groups have been chemically bonded to silicon atoms on the surface of cubic Im3m mesoporous silica. The influence of the release rate of atenolol molecules from chemically modified mesoporous SBA-16 could be identified, since significant differences could be observed among the release patterns of the different materials.
\end{abstract}

\section{Introduction}

Ordered mesoporous silica are interesting solid supports due to their uniform and large pores, tunable pore sizes, highsurface areas, and the presence of a large number of highly dispersed active sites on the pore walls and surface [13]. A series of inorganic mesostructures, such as MCM41, HMS, and SBAn, among others, have been synthesized with different templating schemes $[4,5]$. Among these SBA-type silica materials, SBA-16 is considered to be the most interesting mesostructure, as it contains a 3D cubic arrangement of mesopores, corresponding to the $\mathrm{Im} 3 \mathrm{~m}$ space group, as well as a promising material for a large range of applications, especially as biomaterials, due to its spherical morphology [6, 7].

For application in drug delivery systems, the development of mesoporous materials with well-arranged structures offers new possibilities to incorporate biological agents within silica samples and control the kinetics of their release from the matrix $[8,9]$. The feasibility of SBA- 15 has recently been proven as a system for the controlled release of different drugs $[10,11]$. Some of these previous works have revealed that the chemistry of the walls, apart from the surface area and the distribution of pore size is an important characteristic of porous solids [4, 12]. To attain the best control in the release of the drugs and to obtain a greater adsorption of the drugs, modifications of the chemical surface on the host matrices are necessary and crucial. One of the interesting features of ordered mesoporous solids is the multitude of possible modifications that can be used to both adjust surface functionality and change textural properties [13]. Functionalization by either cocondensation of organic species during synthesis or subsequent surface modification allows for the tuning of surface properties and 
thus could provide a higher selectivity for specific controlled delivery $[14,15]$. The latter provides a good preservation of the mesostructure after treatment and advantageous surface properties, such as a higher selectivity of a specific adsorbent.

However, despite the numerous research works focusing on the mesoporous system routes for drug delivery applications, relatively few published works actually address the investigation of the use of a three-dimensional bodycentered cube, such as an SBA-16, on the drug release kinetics. In addition, to our knowledge, no articles have shown this influence through an adequate modification of the surface chemistry of the SBA-16 matrix in the delivery process. Recently, Thomas et al. [16] synthesized SBA-16 nanoparticles in an attempt to load three antiepileptic active substances: Carbamazepine (CBZ), oxcarbazepine (OXC), and rufinamide (RFN). An easy and simplified method was developed by $\mathrm{Hu}$ et al. [6], who investigated the synthesis of SBA-16 with both a spherical morphology and a controllable pore size for drug release. Their results showed the possibility of establishing the relationship between the pore size and indomethacin delivery properties of SBA-16. Nevertheless, particularly the reported above had limitations as controlled drug release device, presenting a major problem as far as drug release is concerned-limited control of its drug release, which occurs mainly by interaction between silanol groups and drug. As mentioned above, the need to develop materials with optimal tailored characteristics for application as a drug release device lead to functionalization processes. These processes are so complex that they warrant further study, particularly regarding the different kinds of possible solvents used.

Due to the potential application of the 3D cubic-ordered arrangement of mesostructured silica, the present study examined the influence of the presence of organic species on the surface of SBA-16 on the behavior of this system as a controlled drug release device. To accomplish this purpose, mesoporous silica SBA-16 was chemically modified with an alkoxysilane (propyltriethoxysilane) and solvents with different solubility parameters (methanol and toluene). An experiment of drug release was performed to show the effect of the chemical modification in the diffusion rate of atenolol (a model drug) from the silica matrix by introducing an organic compound onto the surface of the silica.

\section{Materials and Methods}

2.1. Materials. Tetraethyl orthosilicate (TEOS), propyltriethoxysilane (PTES), atenolol, and Pluronic F127 (Mav = 12600) were purchased from Sigma Aldrich (São Paulo, Brazil).

2.2. Synthesis of Mesoporous Silica SBA-16. Silica-block copolymer mesophases were synthesized using Pluronic F127 (poly(ethylene oxide)-block-poly(propylene oxide)-blockpoly(ethylene oxide) ), Mav $=12600$, as a templating agent at room temperature. In a typical preparation, $3.0 \mathrm{~g}$ of Pluronic P127 was dissolved in $144 \mathrm{~mL}$ of water and $13.9 \mathrm{~mL}$ of $38 \% \mathrm{HCl}$ solution under constant stirring at $25^{\circ} \mathrm{C}$. After approximately 30 minutes, $11 \mathrm{~mL}$ of cosurfactant butanol was added to reach a $1: 3(\mathrm{~F} 127: \mathrm{BuOH})$ mass ratio in the ternary system. Next $15.3 \mathrm{~mL}$ of tetraethyl orthosilicate (TEOS, Sigma-Aldrich) was added to the solution under constant stirring at $45^{\circ} \mathrm{C}$ for $24 \mathrm{~h}$, according to the method reported by Gobin [17]. After aging at $100^{\circ} \mathrm{C}$ for $24 \mathrm{~h}$ in a hermetically closed recipient, the solids were collected by filtration and dried in open air at $40^{\circ} \mathrm{C}$. The surfactant was removed by calcination, which was carried out by increasing the temperature to $550^{\circ} \mathrm{C}$ under a constant nitrogen flow for 5 hours. Chemical analysis showed that the surfactant had been completely removed by this thermal treatment.

2.3. Silica SBA-16 Functionalization Process. The functionalization process was performed through reaction, under reflux, between the calcined mesoporous material and alcoxysilane (propyltriethoxysilane-PTES, Sigma Aldrich) in two different solvents (methanol and toluene), according to the method described by Izquierdo-Barba et al. [4]. Briefly, $5 \mathrm{~g}$ of calcined mesoporous material was kept under Argon atmosphere, with $4 \mathrm{meq}$ of alcoxysilane PTES, in $30 \mathrm{~mL}$ of solvents, during $24 \mathrm{~h}$ at a controlled temperature.

\subsubsection{Physicochemical and Morphological Characterization of} SBA-16. All samples of SBA-16 and functionalized SBA16 were physicochemical characterized by small-angle $\mathrm{X}$ ray diffraction (XRD), thermogravimetric analysis (TGA), Fourier transform infrared spectroscopy (FTIR), elemental analysis $(\mathrm{CHN}), \mathrm{N}_{2}$ adsorption, and solid state nuclear magnetic resonance (NMR), and were morphologically characterized by TEM techniques.

Nitrogen adsorption isotherms of samples were obtained at $77 \mathrm{~K}$ using a Quantachrome Nova 2200 adsorption analyzer. Before the adsorption measurements, SBA-16 and functionalized samples were outgassed for $2 \mathrm{~h}$ at $120^{\circ} \mathrm{C}$ before analysis. All data analyses were performed using the NovaWin V.10, 1997-2007 Quantachrome Instruments software (Boynton Beach, FL, USA). The weight loss of the samples was determined in a Shimadzu thermogravimetric analyzer (TGA) 50WS. All measurements were carried out within a nitrogen atmosphere $\left(20 \mathrm{~mL} \mathrm{~min}^{-1}\right)$ using a sample mass of approximately $3 \mathrm{mg}$ from room temperature to $873 \mathrm{~K}$ at $283 \mathrm{~K} \mathrm{~min}^{-1}$. The small-angle XRD patterns were obtained using synchrotron radiation. The incident $\mathrm{X}$-ray was set at a wavelength of $1.488 \AA$, while the angle scattering $2 \theta$ ranged from $0^{\circ}$ to $5^{\circ}$. Synchrotron radiation measurements were carried out at the D11A-SAXS beamline of LNLS (Campinas, Brazil). The typical functional groups of the silica network and surface modification were characterized by FTIR. The procedure was conducted in a Thermo, Nicolet 6700 spectrophotometer, ranging from 4000 to $400 \mathrm{~cm}^{-1}$ with 64 scans and $4 \mathrm{~cm}^{-1}$ of resolution. The solid state NMR spectra were recorded in an AC 300/P Burker spectrometer at $75.46 \mathrm{MHz}$ for ${ }^{13} \mathrm{C}$ and $59.54 \mathrm{MHz}$ for ${ }^{29} \mathrm{Si}$ with a Bruker CPMAS probe using $4 \mathrm{~mm} \mathrm{ZrO}_{2}$ rotors at a spinning rate of $10 \mathrm{kHz}$. The technique of cross polarization (CP) it was used with magic angle rotation (MAS) and relaxation times of $60 \mathrm{~s}$ and $3 \mathrm{~s}$ for silicon and carbon, respectively. Contact 
time was $4 \mathrm{~ms}$. The functionalization rate was determined by elemental analysis, which was performed in a Perkin-Elmer CHNS, O, model 2400. Transmission electron micrographs (TEM) were recorded on a Tecnai G2-Spirit-FEI-2006 microscope operating at $120 \mathrm{k}$. Images were recorded by CCD camera and were analyzed with software iTEM from Analysis.

2.4. Drug Loading and In Vitro Release Study. Atenolol was used as a model drug to evaluate the performance of the SBA16 and the functionalized mesoporous materials' capacity to host pharmaceuticals. Atenolol $\left(\mathrm{C}_{14} \mathrm{H}_{22} \mathrm{~N}_{2} \mathrm{O}_{3}\right)$ is a betaadrenoceptor antagonist or, as more commonly known, a beta-blocker. It is a relatively polar hydrophilic compound with a water solubility of $26.5 \mathrm{mg} / \mathrm{mL}$ at $25^{\circ} \mathrm{C}$ and has been used to treat hypertension, to prevent angina (chest pain), and to treat heart attacks. The samples powders $(500 \mathrm{mg}$ ) were soaked in an aqueous solution of atenolol $(1 \mathrm{mg} / \mathrm{mL})$ for 2 days at room temperature in a $3: 1$ proportion $(\mathrm{w} / \mathrm{w})$, mesoporous matrices and drug, respectively. The in vitro release profile was obtained by soaking the samples (100 mg) in $30 \mathrm{~mL}$ of a simulated body fluid (SBF) for $24 \mathrm{hs}$ at room temperature. The UV spectrometry procedure (Shimadzu UV-VIS V-2401) was used to monitor the amount of atenolol loaded and released as a function of time. The solutions were continuously stirred, and the concentration of atenolol in SBF was determined by the intensity of the absorption band at $274 \mathrm{~nm}$.

\section{Statistical Analysis}

The results were calculated and presented as the mean for each group \pm standard error of the mean (mean \pm S.D.). Statistical evaluation of the data was performed using the analysis of variance (ANOVA), followed by the Tukey's test (posthoc), where $P<0.05$ was considered to be statistically significant.

\section{Results and Discussion}

4.1. Functionalization Rate. The elemental analysis of $\mathrm{CHN}$ in the SBA-16 matrix and the functionalized mesoporous material samples were used to quantify the organic molecules anchored in its surfaces. The results are shown in Table 1 . The functionalized samples, when in the presence of methanol and toluene, showed higher carbon concentrations in PTES, as compared to the SBA-16 matrix, confirming the presence of anchored functionalized agents on its surfaces. By comparing the results of the functionalized agent used and pure SBA16 , it could be observed that the samples functionalized with PTES presented higher carbon content (9.75\% using toluene and $5.56 \%$ using methanol) than did SBA-16 sample.

The functionalized materials using toluene as a solvent, as compared to the functionalized materials using methanol, exhibit a higher percentage of carbon. The type of solvent, therefore, produces a crucial impact on the adsorption of the alkoxysilane on the mesoporous silica surface. An analysis of this data, considering the solubility parameter $(\delta)$ of the different solvents, can aid in understanding these results, since the solubility parameter is related to the solvent polarity. Generally, the polarity parameter increases with the increase in $\delta$. On the basis of the intermolecular interactions, the $\delta$ parameters are grouped into several parameters such as $\delta d$ for dispersion interactions, $\delta o$ for dipole interactions, and $\delta a$ for hydrogen-bonding interactions. These parameters are good indices to reveal the solubility of solvents for specific substances.

Considering that methanol has a dipole moment of $1.69 \delta a$, while toluene presents a value of $0.36 \delta a$, the following explanation for the previously described results can be hypothesized as follows. When PTES is in the presence of alcohol, hydrogen bonds are possible at three different points within the central region of the molecule, allowing for more interactions to occur between the solvent and the functionalized agent [18]. However, when using toluene as a solvent, Van der Waals intermolecular forces on the outer portions of the molecule are presented due to the low dipole moment of the solvent (Figure 1).

During the functionalization of the silica, both solvent and organic groups compete for reaction with the surface silanol groups present in the pores by means of an interaction with PTES generated through hydrogen bonds. When PTES is used in toluene, a preference of hydrogen bonding occurs between the central region of PTES and the silanol groups of silica rather than weak Van der Waals forces on the periphery. As such, the molecules of the PTES are more thermodynamically stabilized by hydrogen bonds than by the Van der Waals interactions within the solvent. This behavior explains the higher degree of the functionalization of the silica in the presence of toluene than in methanol. Moreover, there is a direct competition of alcohol molecules with silanol groups, indicating that this chemical bond is more stable, making a huge loss in the functionalization process when methanol is used as a solvent.

4.2. Thermal Analysis. The amount of alcoxysilane groups loaded in the SBA-16 host was determined by thermogravimetry. The TGA curves of all systems are shown in Figure 2, and the results are summarized in Table 1 . The pure SBA-16 shows an initial weight loss of $13 \%$, from $25^{\circ} \mathrm{C}$ to $150^{\circ} \mathrm{C}$, which is apparently due to surface dehydration. Above $150^{\circ} \mathrm{C}$ and up to $600^{\circ} \mathrm{C}$ no significant weight loss could be identified. As a result, the SBA-16 showed excellent thermal stability within the investigated temperature range.

Concerning the functionalized samples, weight loss occurred in two distinct regions for all samples. The first region of mass loss occurred within the temperatures ranging from $25^{\circ} \mathrm{C}$ to $150^{\circ} \mathrm{C}$, which can be attributed to the thermodesorption of physically adsorbed water. The second region showed weight loss within the temperatures ranging from $150^{\circ} \mathrm{C}$ to $600^{\circ} \mathrm{C}$, which can be attributed to the decomposition temperature of incorporated groups. The presence of the hydrocarbon chain confers the pore surface a rather apolar character. As a consequence, the mass loss in the first region is much lower for the functionalized sample than for the pure samples, due to its lower surface 


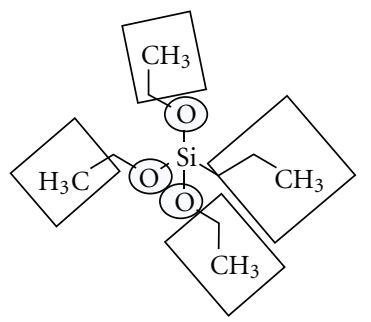

(a)

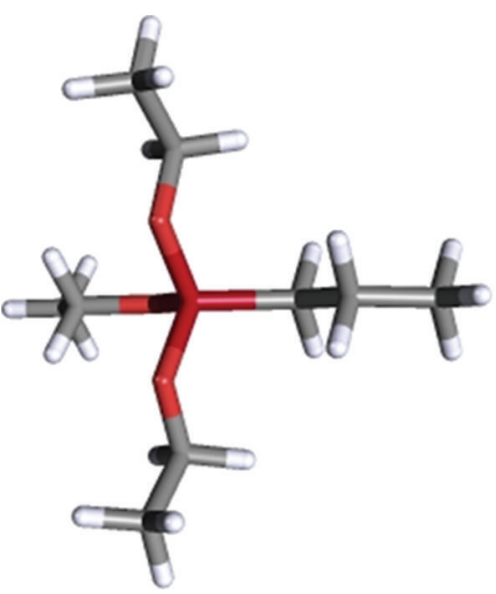

(b)

FIgURE 1: (a) Molecular structure of n-propyltriethoxysilane. Circular areas are hydrogen bond acceptor regions. Square areas are Vander Waals forces predominance regions. (b) 3D conformer viewer showing a central more polar region and peripheral unpolar regions. Images Adapted from PubChem substances.

TABLE 1: Weight loss and amount of carbon.

\begin{tabular}{lcccc}
\hline Sample & $\begin{array}{c}\text { Weight loss }(\% \mathrm{w} / \mathrm{w}) \\
25-150^{\circ} \mathrm{C}\end{array}$ & $\begin{array}{c}\text { Weight loss }(\% \mathrm{w} / \mathrm{w}) \\
150-600\end{array}$ & $\begin{array}{c}\text { Residue }(\% \mathrm{w} / \mathrm{w}) \\
600^{\circ} \mathrm{C}\end{array}$ & $\begin{array}{c}\text { Carbon } \\
\mathrm{mmol} \cdot \mathrm{g}^{-1}\end{array}$ \\
\hline SBA-16 & 13.1 & - & 85 & $0.257 \pm 0.058$ \\
M-PTES & 3.4 & 2.8 & 93 & $2.113 \pm 0.012$ \\
T-PTES & 1.3 & 7.2 & 91 & $7.883 \pm 1.097$ \\
\hline
\end{tabular}

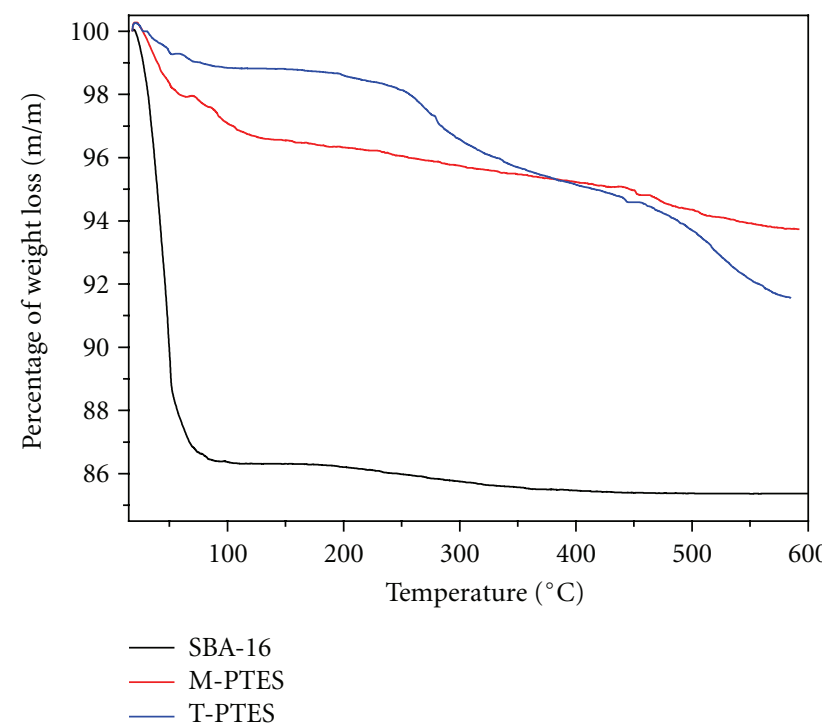

Figure 2: TGA curves of SBA-16, T-PTES and M-PTES.

hydration. By contrast, modified SBA-16 materials, using toluene as a solvent, present a weight loss of up to $7.2 \%$ and $11.4 \%$ at temperatures of above $150^{\circ} \mathrm{C}$. This weight loss can be ascribed to the decomposition and total loss of the alcoxysilane groups from the materials, based on the fact that there is almost no significant weight loss in the parent

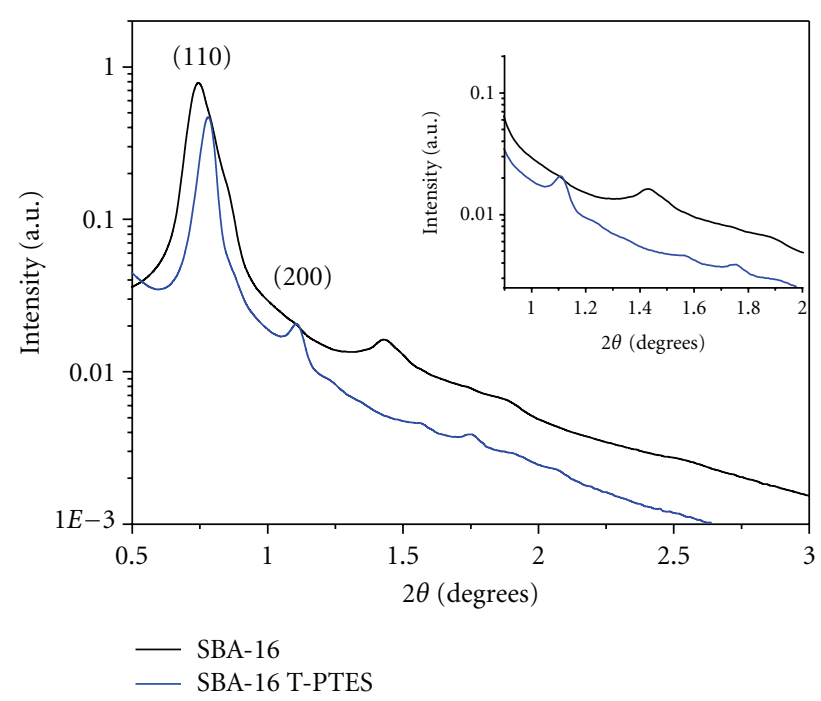

FIGURE 3: SAXS patterns of calcined SBA-16 functionalized with PTES in toluene $(\mathrm{T})$.

SBA-16 silica in this same temperature range [19]. However, since the decomposition temperature for the incorporated alcoxysilane groups is above $150^{\circ} \mathrm{C}$, it can be concluded that the alcoxysilane groups are chemically bonded in the internal surface of the SBA-16 materials and present an adequate thermal stability for the proposed application. 
TABLE 2: Structural parameters for different samples.

\begin{tabular}{lcccc}
\hline Samples & $d_{(110)}(\mathrm{nm})$ & $a_{110}(\mathrm{~nm})$ & $h(\mathrm{~nm})$ & SBET $\left(\mathrm{m}^{2} / \mathrm{g}\right)$ \\
\hline SBA16 & 11.43 & 16.16 & 12.56 & 550 \\
M-PTES & 10.89 & 15.39 & 11.69 & 549 \\
T-PTES & 10.85 & 15.34 & 11.64 & 311 \\
\hline
\end{tabular}

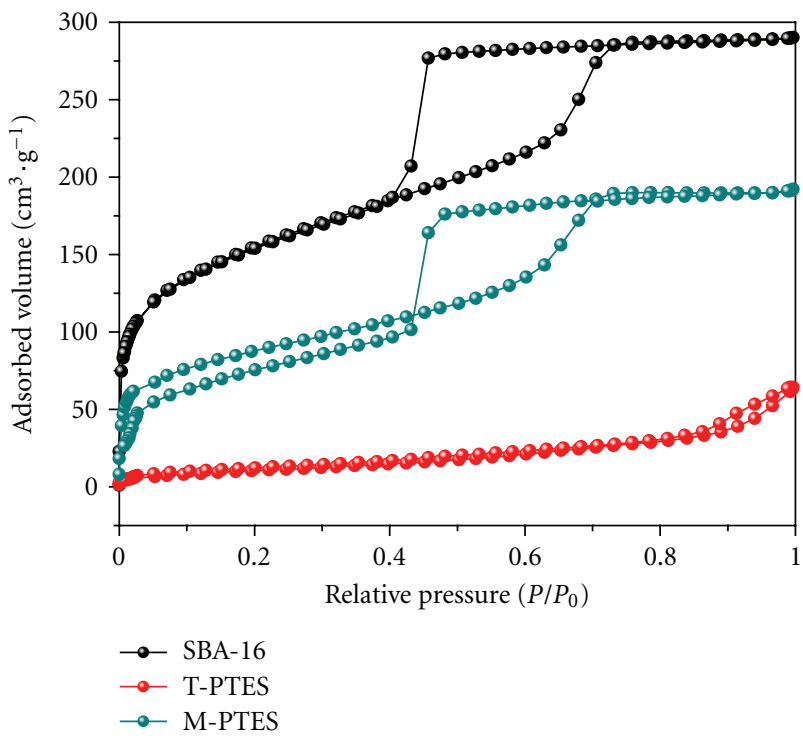

FIGURE 4: Nitrogen adsorption/desorption isotherms of pure SBA16 and functionalized samples.

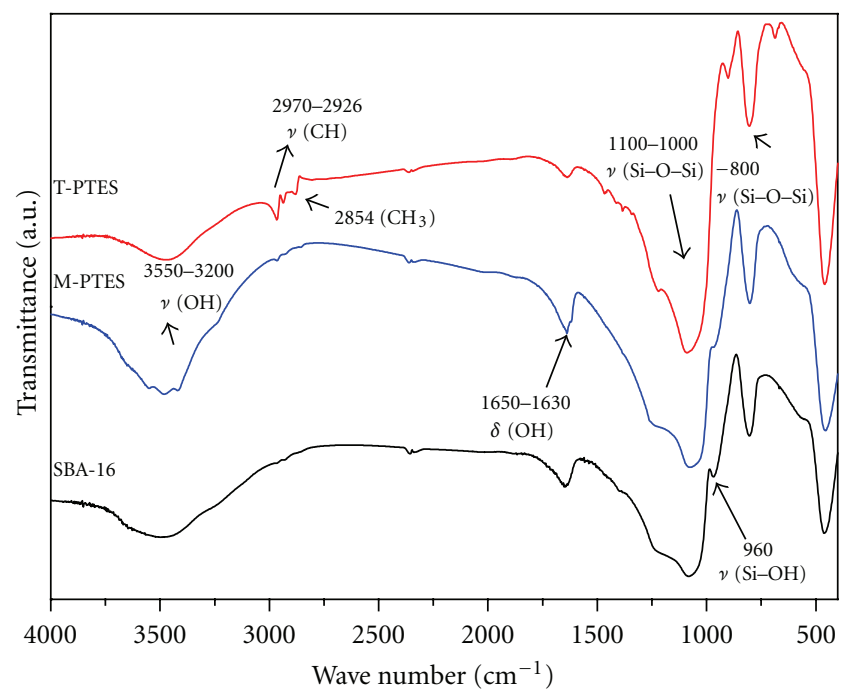

FIgure 5: FTIR spectra SBA-16, T-PTES, and M-PTES samples.

\subsection{Physicochemical and Morphological Characterization of SBA-16}

4.3.1. SAXS. Small-angle XRD of SBA-16 shows a wellresolved pattern with (110), (200), and (211) reflections and characteristics of the 3D cubic mesoporous structure ( $\mathrm{Im} 3 \mathrm{~m}$ plain group) with $d_{110}$ spacing of $11.4 \mathrm{~nm}$ (Figure 3 ).
This structure is characteristic of body-centered cubic [20], corresponding to a large unit cell parameter of $a_{0}=$ $16.1 \mathrm{~nm}\left(a=d\left({ }_{110}\right) \times \sqrt{ } 2\right)$, which is in accordance with reported patterns of pure siliceous SBA-16 materials [21]. The SAXS patterns of surface modified samples indicate that the functionalization of the pore wall does not affect the structural order, showing $d\left({ }_{110}\right)$ values of $\sim 11.0 \pm 0.2 \mathrm{~nm}$. The small-angle XRD profiles are similar to that of calcined SBA-16 (see Figure 3 ). The values of $d, a_{0}$, and $h$ (pore wall thickness) found for the pure and functionalized SBA-16 samples with methanol and toluene are reported in Table 2. The characteristics provided by pore wall thickness, such as higher thermal and hydrothermal stability, were still present in the samples even after functionalization.

4.3.2. Adsorption $\mathrm{N}_{2}$. The nitrogen adsorption isotherms for pure and functionalized SBA-16 samples with methanol and toluene are shown in Figure 4, and Table 2 summarizes the results. According to the IUPAC classification, all the isotherms are type IV, which is associated with the presence of mesopores [22]. SBA-16 contains asymmetrical and triangular adsorption and desorption branches, and these characteristics can be assigned to systems with pore network connectivity and a pore blocking effect, such as "ink-bottle" pores with an H2-type hysteresis loop. As expected, the introduction of the organic moieties leads to a decrease in surface area. This decrease evinces the fact that the organic material is located within the pores of the matrix; that is, it shows that the pore wall is indeed covered by organic moieties. The pore size distribution curve of pure and modified SBA-16 presents a very narrow pore size distribution mesopore at around of $3.7 \mathrm{~nm}$ (not shown), calculated by using the $\mathrm{BJH}$ computation procedure.

4.3.3. FTIR. To determine the chemical composition of obtained SBA-16 matrices and the presence of alcoxysilane groups as functionalization agents on the wall surface, the Fourier transform infrared spectroscopy technique was employed and the results of which are presented in Figure 5. The bands that are typical of mesoporous silica are widely reported in the literature and can be easily identified in Figure 5 [9]. Hence, the vibrational band at approximately $960 \mathrm{~cm}^{-1}$ has been credited to the presence of silanol groups ( $\mathrm{Si}-\mathrm{OH})$ commonly found in silica synthesized by means of chemical methods. This peak presented some alterations after the functionalization process. As the consumption of silanol groups during the interaction of the alkoxysilanes with the surface of the SBA-16 was expected, a careful comparison between the spectra before and after the functionalization indicated that the band at $960 \mathrm{~cm}^{-1}$ shows 


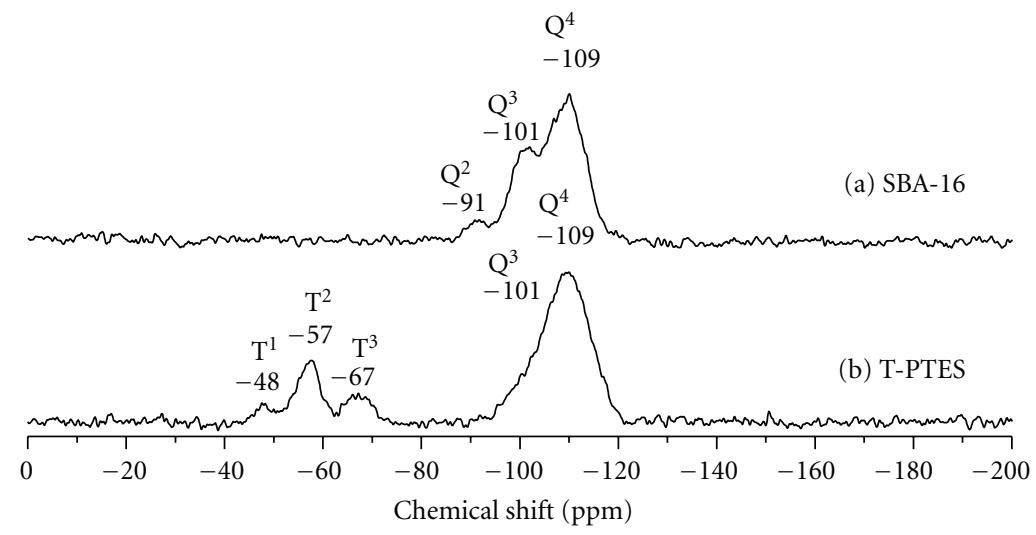

Figure 6: RMN spectra of (a) ${ }^{29} \mathrm{Si}$ of SBA-16, (b) ${ }^{29} \mathrm{Si}$ of T-PTES.

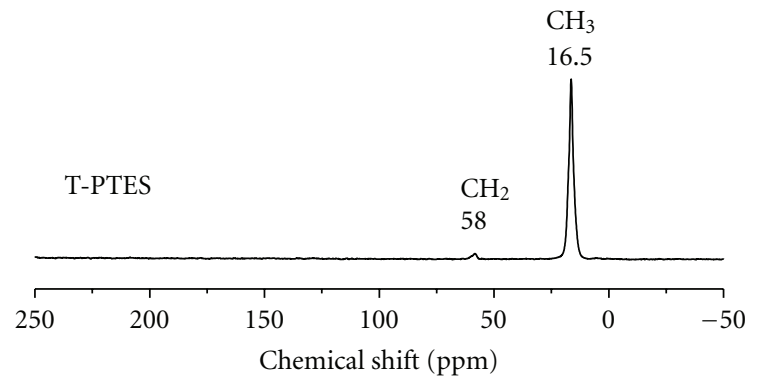

Figure 7: RMN spectra of ${ }^{13} \mathrm{C}$ of T-PTES.

a significant decrease in intensity in the functionalized samples with T-PTES and a smaller difference for $\mathrm{M}$ PTES. This fact indicates that the adsorption of organic groups on the silica surface occurs simultaneously with the disappearing of hydroxyl groups. In fact, some differences among the infrared spectra can be observed in Figure 5, such as an absorption band at $2854 \mathrm{~cm}^{-1}$, which is typical of $\mathrm{CH}_{3}$ groups on the silica surface in the functionalized samples. Moreover, absorptions band located at 2970 and $2926 \mathrm{~cm}^{-1}$ can be attributed to the alkyl stretching mode $(\nu \mathrm{CH})$. Differences in the relative intensity of the $\mathrm{CH}_{2}$ bands are observed as a function of the nature of the solvent used in the functionalization procedure, as discussed above. These infrared results indicate the formation of $\mathrm{Si}-\mathrm{O}-\mathrm{CH}_{3}$ and $\mathrm{Si}-$ $\mathrm{O}-\mathrm{Si}-\mathrm{R}$ groups due to the process of surface modification.

4.3.4. RMN. Figure 6 shows the solid-state ${ }^{29} \mathrm{Si}$ CPMAS NMR spectra of the pure and functionalized SBA-16 silica. The ${ }^{29} \mathrm{Si}$ CPMAS NMR spectrum of the parent SBA-16 silica (Figure 6(a)) can be seen in broad peaks and dominated by an intense line at $-110 \mathrm{ppm}$ along with two shoulders at -101 and -91 ppm. By analogy to zeolites and amorphous silica materials, the chemical shift at $-110 \mathrm{ppm}$ can be assigned to $\mathrm{Si}(\mathrm{OSi})_{4}\left(\mathrm{Q}^{4}, \mathrm{Q}^{n}=\mathrm{Si}(\mathrm{OSi})_{n}(\mathrm{OH})_{4-n}, n \leq 4\right)$ structural units, while the lines at -101 and $-91 \mathrm{ppm}$ can be compared to $\mathrm{Si}(\mathrm{OSi})_{3} \mathrm{OH}\left(\mathrm{Q}^{3}\right)$ and $\mathrm{Si}(\mathrm{OSi})_{2}(\mathrm{OH})_{2}$
TABLE 3: Loading rate of atenolol into SBA-16 silica, M-PTES, and T-PTES samples. Means followed by same letters differ at the $P<$ 0.01 . For different letters differ at the $P<0.001$.

\begin{tabular}{lc}
\hline Sample & Loading rate $(\% \mathrm{w} / \mathrm{w}) \pm S D$. \\
\hline SBA-16 & $21.0 \pm 0.90 .9^{\mathrm{a}}$ \\
M-PTES & $22.0 \pm 0.80 .8^{\mathrm{b}}$ \\
T-PTES & $16.4 \pm 0.30 .3^{\mathrm{b}}$ \\
\hline
\end{tabular}

$\left(\mathrm{Q}^{2}\right)$ structural units, respectively. The $\mathrm{Q}^{4}$ structural units represent interlinked $\mathrm{SiO}_{4}$ tetrahedrons in the interior of the mesopore walls, while $\mathrm{Q}^{3}$ and $\mathrm{Q}^{2}$ structural units are present on the wall surface associated with silanol groups [23]. In contrast to the parent SBA-16 silica, the ${ }^{29} \mathrm{Si}$ CPMAS NMR spectra of modified SBA-16 materials show only a broad line centered at $-110 \mathrm{ppm}$ due to $\mathrm{Q}^{4}$ structural units, while the lines at -101 and $-91 \mathrm{ppm}$ due to $\mathrm{Q}^{3}$ and $\mathrm{Q}^{2}$ structural units are missing (Figure 6(b)).

Figure $6(\mathrm{~b})$ shows ${ }^{29} \mathrm{Si}$ de NMR spectrum of the modified SBA-16 materials with propyltriethoxysilane. The T-PTESfunctionalized SBA-16 sample contains four different silicon chemical environments: $\mathrm{Q}^{4}, \mathrm{~T}^{1}, \mathrm{~T}^{2}$, and $\mathrm{T}^{3}$. The resonance peaks assigned to $\mathrm{Q}^{4}(\delta=-109 \mathrm{ppm})$ can be observed. Three resonance peaks related to the " $T$ " species can also be seen with chemical shifts of $\delta=-47 \mathrm{ppm}$ for $\mathrm{T}^{1},-57 \mathrm{ppm}$ for $\mathrm{T}^{2}$, and $\delta=-67 \mathrm{ppm}$ for $\mathrm{T}^{3}$. This result confirms the incorporation of the organosilane within the silica network.

The ${ }^{13} \mathrm{C}$ CP-MAS spectrum (Figure 7 ) shows the carbon chemical environments of the T-PTES samples. This sample displays resonance peaks with chemical shifts of $\delta=16.5$ and 58 assigned to $\mathrm{CH}_{3}$ and $\mathrm{CH}_{2}$, respectively. These two peaks are attributed to carbon species due to organic groups [24].

4.3.5. TEM. The TEM images of the parent SBA-16 silica are shown in Figure 8(a). These images presented a cubic array of uniform channels when the incident electron beam was parallel to the main axis of the mesopores and unidirectional 

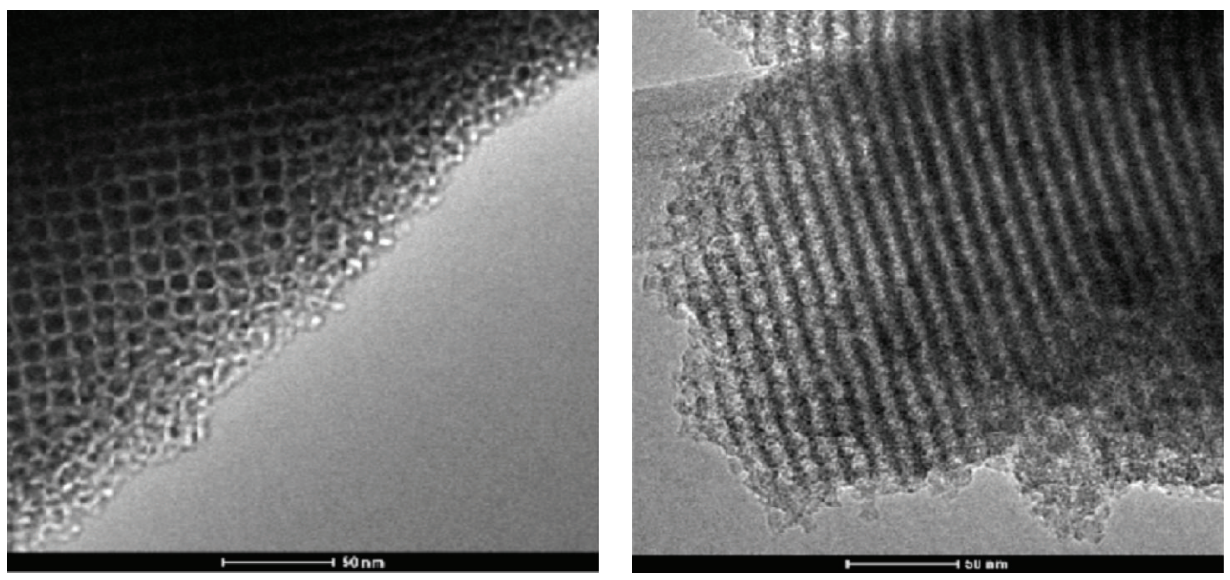

(a)
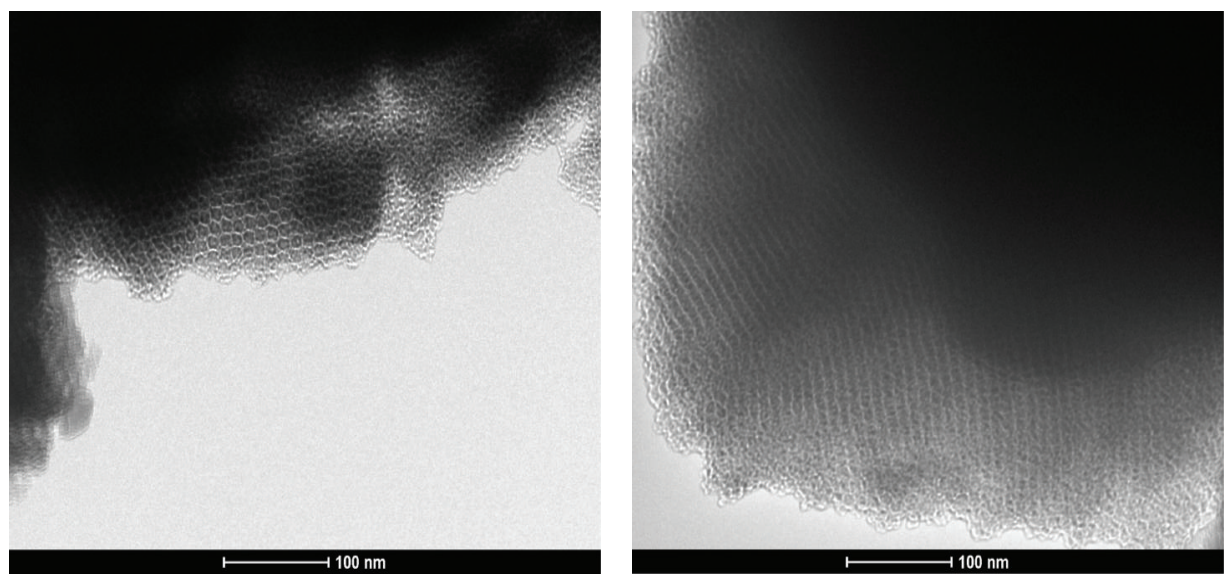

(b)

FIgURE 8: TEM images of (a) SBA-16 sample and (b) T-PTES sample.

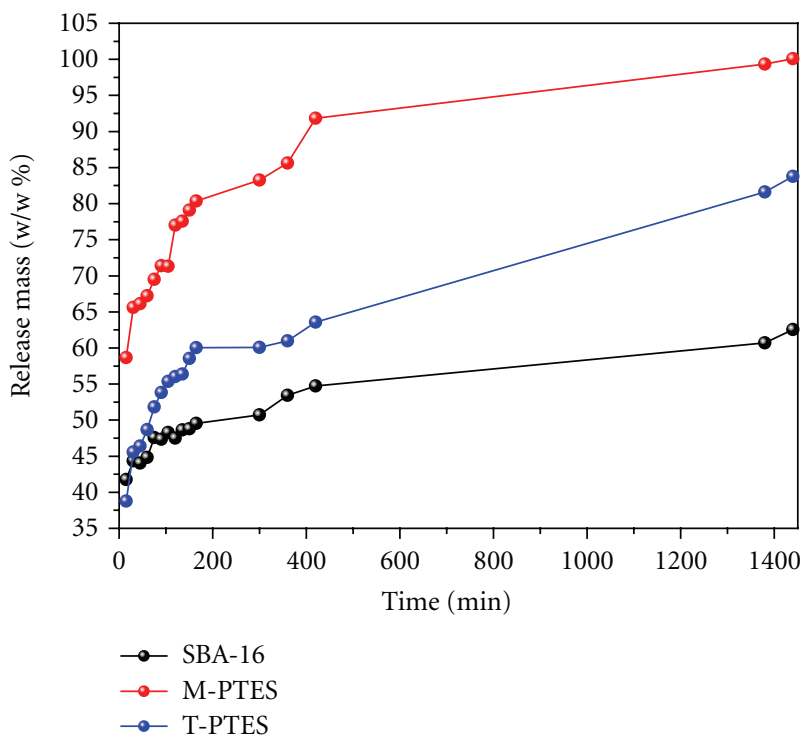

FIgURE 9: Release profiles of atenolol from SBA-16 parent mesoporous matrices and modified matrix. channels when the electron was perpendicular to the channel axis. The unit cell parameter was approximately (15.2 \pm $0.7) \mathrm{nm}$, which is in agreement with the SAXS data. The TEM images from modified SBA-16 materials with propyl groups (Figure 8(b)) showed no significant difference in the spacing between channels from one of the parent SBA-16 silica, thus proving that the ordered structure is preserved in the approach proposed in the present work to obtain a functionalized mesoporous material. Sakamoto et al. [20] reported the pore structure of the SBA-16 through HREM images for (100), (110), and (111) incidences, as well as the corresponding Fourier diffractograms of the images from thin areas. The morphology of the observed crystals of this material is simply cubic, indicating a point group of $\mathrm{m} 3 \mathrm{~m}$ and confirming that $\operatorname{Im} 3 \mathrm{~m}(a=133 \AA$ ) is a suitable space group [20]. In the present work, similar structures were obtained for both SBA-16 and functionalized samples.

4.4. Drug Loading and Release Study. The uptake of atenolol by different samples was determined by UV-Vis, and Table 3 shows this drug content for pure and functionalized SBA16 samples. The results reveal that the silica SBA-16 and M-PTES samples present a higher amount of the drug 


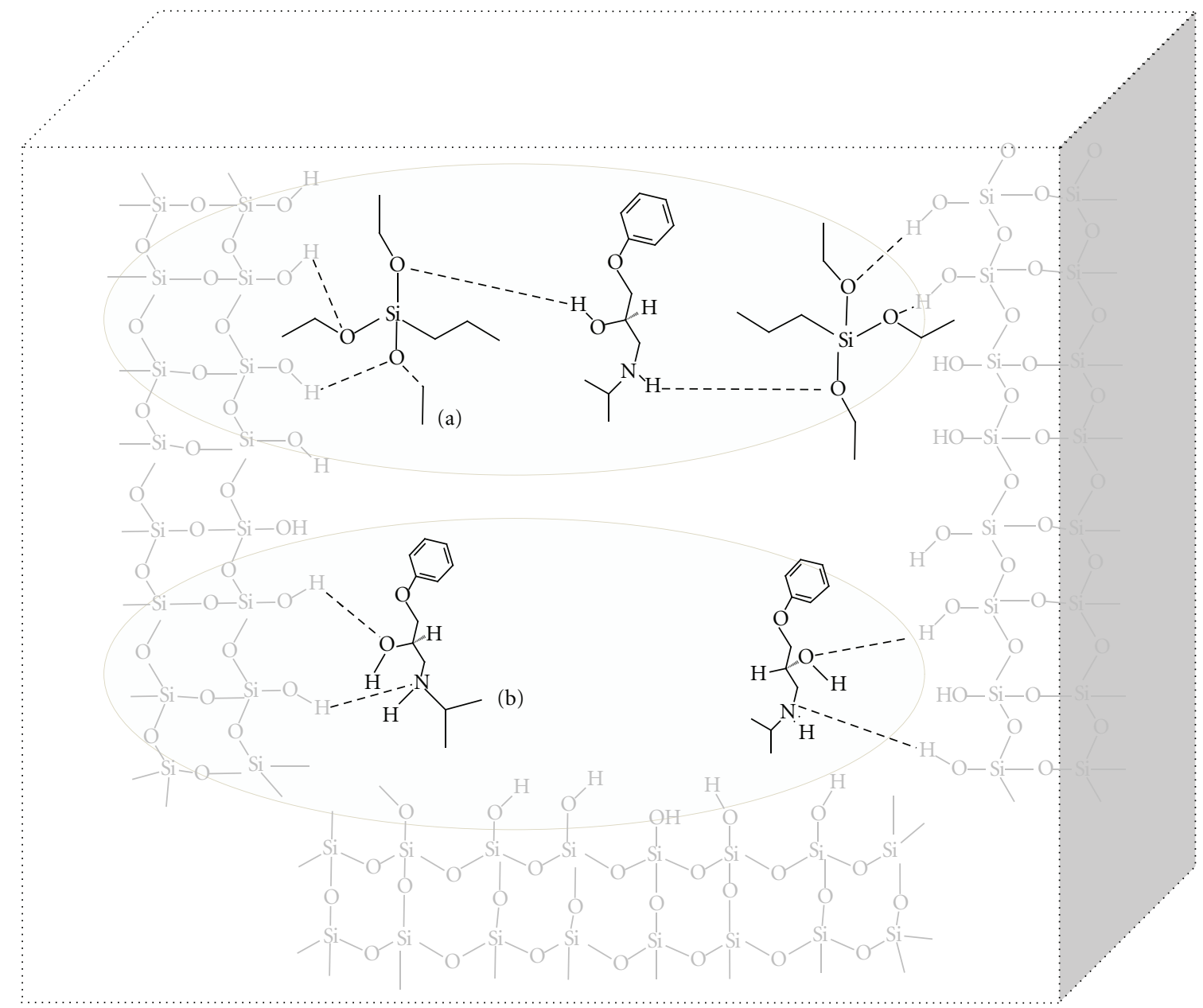

FIGURE 10: Representative scheme of collaborative interactions "anchoring" between the functionalizing agent PTES and atenolol (a). Chemical interactions between the silanols groups of SBA-16 and Atenolol (b).

among the studied samples, which is likely related to more available spaces due to a lack of or a low functionalization rate.

The functionalized sample using toluene as a solvent presented the lowest percentages of atenolol loading, reaching approximately $16 \%(\mathrm{w} / \mathrm{w})$. This behavior can be attributed to a higher degree of functionalization of these samples and, therefore, smaller pore spaces are available for loading, as can be observed by the $\mathrm{N}_{2}$ adsorption results (Table 2). Furthermore, the results show that the amount of atenolol adsorbed in the SBA-16 matrix $(21 \% \mathrm{w} / \mathrm{w})$ remains practically the same, regardless of the M-PTES sample, as no statistically significant differences could be observed $(P>0.05)$ in the loading percentage. This is related to the fact that the pores of the silica matrix with or without a small amount of the functionalizing agent can compete with the drug; thus, more space is available for embedding.

The inclusion of functional groups on silica is, therefore, a well-established procedure [25]. Alkyl is among the most commonly included group; as a result, the ability of a surface to interact through hydrogen bonds or through van der Waals force, electrostatic, or covalent bonds can be manipulated.

The in vitro atenolol released properties from these samples were investigated as a function of time and are shown in Figure 9. It could be observed that atenolol-loaded SBA16 and T-PTES samples did not show a sharp initial burst release during the first hours. On the other hand, the release profiles of M-PTES exhibited a pronounced initial burst release effect of $65 \%$ (under $1 \mathrm{~h}$ ), followed by a slow release pattern. The initial burst release can be attributed to the immediate dissolution and release of the portion of the drug located on or near the surface of the disks. It could also be observed that SBA-16 matrix released a smaller percentage of atenolol than did M-PTES and T-PTES samples. For the MPTES sample, approximately $100 \%$ of the drug was released, whereas the maximum release achieved in 24 hours for the sample of SBA- 16 was $62 \%$, as compared to $83 \%$ for T-PTES, which was greater than the pure sample.

The diffusion model used to study the release kinetics of atenolol from the studied systems was employed according to theoretical analysis from the Korsmeyer-Peppas model 
[26], an empirical exponential expression used to relate drug release with fractional release time (1):

$$
\frac{M_{t}}{M_{\infty}}=K t^{n},
$$

where $M_{t} / M_{\infty}$ is the fractional solute release, $t$ is the release time, $k$ is a constant, and $n$ is the diffusional exponent characteristic of the release mechanism.

The parameters of (1) can be obtained from (2):

$$
\ln \left(\frac{M_{t}}{M_{\infty}}\right)=\ln K+n \ln t
$$

In cases of pure Fickian release, exponent $n$ has the limiting values of $0.5,0.45$, and 0.43 for release from slabs, cylinders, and spheres, respectively. For tablets, and depending on the diameter-thickness ratio, the Fickian diffusion mechanism is described by $0.43<n<0.50$. For drug release from spherical particles with a wide-sized distribution, the value of $n$ for Fickian diffusion depends on the distribution width. The values of the kinetic constant $k$, for T-PTES, SBA16, and M-PTES are presented in Table 4. Comparing all samples studied, the T-PTES sample presented a lower level of atenolol release kinetics.

The use of toluene proved to lead to a higher degree of functionalization of the SBA-16 matrix. This higher degree of functionalization allows for an increase in the number of interactions of hydrogen bonds between the functionalized agent and atenolol, as demonstrated in Figure 10(a). By contrast, in the absence of functionalized agents, the drug is anchored only by interactions with silanol groups (Figure 10(b)), thereby providing interactions of lesser magnitude, in turn resulting in faster release kinetics (see Table 4).

\section{Conclusion}

In summary, we have successfully synthesized the ordered arrangement of $3 \mathrm{D}$ cubic of mesostructured silica, SBA16, and chemically modified it with alkoxysilane. The applicability of these systems as a matrix for controlled drug delivery was also studied. The cubic mesoporous material, SBA-16, proved to be a suitable matrix for the adsorption and in vitro release of atenolol. An effective control of the release rate of this antihypertensive has been achieved by functionalizing the surface of the SBA-16 with hydrophobic chain hydrocarbon moieties. The type of solvent used produces a crucial impact on the adsorption of alkoxysilane on silica surfaces. The affinity of the alkoxysilane with the solvents is critical, and the solubility parameter can be used as a reference in surface modification processes for specific applications. As a result, for samples which contain $-\mathrm{CH}_{2}$ groups using toluene with solvent, compared to that with calcined SBA-16, the release rate decreases by a factor of nearly one order of magnitude.

\section{Acknowledgments}

This work has been supported by CAPES, CNPq, and FAPEMIG.
TABle 4: Parameters of atenolol release (kinetic Constant- $K$ ).

\begin{tabular}{lcc}
\hline Sample & $K$ & $r^{2}$ \\
\hline T-PTES & 13.9 & 0.98 \\
SBA-16 & 22.4 & 0.96 \\
M-PTES & 25.8 & 0.96 \\
\hline
\end{tabular}

\section{References}

[1] P. Wang, Y. Zhu, X. Yang, C. Li, and H. L. Du, "Synthesis of CdSe nanoparticles into the pores of mesoporous silica microspheres," Acta Materialia, vol. 56, no. 5, pp. 1144-1150, 2008.

[2] S. C. Tsang, R. Burch, S. Nishiyama et al., "Nanoscopic tin oxide films on mesoporous silica as novel catalysts for hydrogen transfer reactions," Nanostructured Materials, vol. 12, no. 5, pp. 999-1002, 1999.

[3] S. Angelos, M. Liong, E. Choi, and J. I. Zink, "Mesoporous silicate materials as substrates for molecular machines and drug delivery," Chemical Engineering Journal, vol. 137, no. 1, pp. 4-13, 2008.

[4] I. Izquierdo-Barba, E. Sousa, J. C. Doadrio et al., "Influence of mesoporous structure type on the controlled delivery of drugs: release of ibuprofen from MCM-48, SBA-15 and functionalized SBA-15," Journal of Sol-Gel Science and Technology, vol. 50, no. 3, pp. 421-429, 2009.

[5] A. Sousa, K. C. Souza, and E. M. B. Sousa, "Mesoporous silica/apatite nanocomposite: special synthesis route to control local drug delivery," Acta Biomaterialia, vol. 4, no. 3, pp. 671679, 2008.

[6] Y. Hu, J. Wang, Z. Zhi, T. Jiang, and S. Wang, "Facile synthesis of $3 \mathrm{D}$ cubic mesoporous silica microspheres with a controllable pore size and their application for improved delivery of a water-insoluble drug," Journal of Colloid and Interface Science, vol. 363, no. 1, pp. 410-417, 2011.

[7] Y. Hu, Z. Zhi, Q. Zhao et al., "3D cubic mesoporous silica microsphere as a carrier for poorly soluble drug carvedilol," Microporous and Mesoporous Materials, vol. 147, no. 1, pp. 94$101,2012$.

[8] A. Sousa and E. M. B. Sousa, "Influence of synthesis temperature on the structural characteristics of mesoporous silica," Journal of Non-Crystalline Solids, vol. 352, no. 32-35, pp. 3451-3456, 2006.

[9] J. C. Doadrio, E. M. B. Sousa, I. Izquierdo-Barba, A. L. Doadrio, J. Perez-Pariente, and M. Vallet-Regí, "Functionalization of mesoporous materials with long alkyl chains as a strategy for controlling drug delivery pattern," Journal of Materials Chemistry, vol. 16, no. 5, pp. 462-466, 2006.

[10] S. Wang, "Ordered mesoporous materials for drug delivery," Microporous and Mesoporous Materials, vol. 117, no. 1-2, pp. $1-9,2009$.

[11] I. I. Slowing, J. L. Vivero-Escoto, C. W. Wu, and V. S. Y. Lin, "Mesoporous silica nanoparticles as controlled release drug delivery and gene transfection carriers," Advanced Drug Delivery Reviews, vol. 60, no. 11, pp. 1278-1288, 2008.

[12] X. Diao, Y. Wang, J. Zhao, and S. Zhu, "Effect of poresize of mesoporous SBA-15 on adsorption of bovine serum albumin and lysozyme protein," Chinese Journal of Chemical Engineering, vol. 18, no. 3, pp. 493-499, 2010.

[13] L. Calvillo, V. Celorrio, R. Moliner, P. L. Cabot, I. Esparbé, and M. J. Lázaro, "Control of textural properties of ordered mesoporous materials," Microporous and Mesoporous Materials, vol. 116, no. 1-3, pp. 292-298, 2008. 
[14] M. Manzano, V. Aina, C. O. Areán et al., "Studies on MCM41 mesoporous silica for drug delivery: effect of particle morphology and amine functionalization," Chemical Engineering Journal, vol. 137, no. 1, pp. 30-37, 2008.

[15] P. Yang, Z. Quan, L. Lu, S. Huang, and J. Lin, "Luminescence functionalization of mesoporous silica with different morphologies and applications as drug delivery systems," Biomaterials, vol. 29, no. 6, pp. 692-702, 2008.

[16] M. J. K. Thomas, I. Slipper, A. Walunj et al., "Inclusion of poorly soluble drugs in highly ordered mesoporous silica nanoparticles," International Journal of Pharmaceutics, vol. 387, no. 1-2, pp. 272-277, 2010.

[17] O. S. Gobin, SBA-16 Materials Synthesis, Diffusion and Sorption Properties, Laval University, 2006.

[18] M. Belmares, M. Blanco, W. A. Goddard et al., "Hildebrand and hansen solubility parameters from molecular dynamics with applications to electronic nose polymer sensors," Journal of Computational Chemistry, vol. 25, no. 15, pp. 1814-1826, 2004.

[19] J. G. P. Espínola, L. N. H. Arakaki, S. F. De Oliveira, M. G. Da Fonseca, J. A. A. Campos Filho, and C. Airoldi, "Some thermodynamic data of the energetics of the interaction cation-piperazine immobilized on silica gel," Colloids and Surfaces A, vol. 221, no. 1-3, pp. 101-108, 2003.

[20] Y. Sakamoto, M. Kaneda, O. Terasaki et al., "Direct imaging of the pores and cages of three-dimensional mesoporous materials," Nature, vol. 408, no. 6811, pp. 449-453, 2000.

[21] R. M. Grudzien, B. E. Grabicka, and M. Jaroniec, "Adsorption studies of thermal stability of SBA-16 mesoporous silicas," Applied Surface Science, vol. 253, no. 13, pp. 5660-5665, 2007.

[22] K. S. W. Sing, D. H. Everett, R. A. W. Haul et al., "Reporting physisorption data for gas/solid systems with special reference to the determination of surface area and porosity," Pure and Applied Chemistry, vol. 57, no. 4, pp. 603-619, 1985.

[23] A. El Kadib, P. Hesemann, K. Molvinger et al., "Hybrid materials and periodic mesoporous organosilicas containing covalency bonded organic anion and cation featuring MCM41 and SBA-15 structure," Journal of the American Chemical Society, vol. 131, no. 8, pp. 2882-2892, 2009.

[24] A. Matsumura, T. Zhang, K. Nakai et al., "Combination of boron and gadolinium compounds for neutron capture therapy. An in vitro study," Journal of Experimental and Clinical Cancer Research, vol. 24, no. 1, pp. 93-98, 2005.

[25] B. P. Nair and C. Pavithran, "Bifunctionalized hybrid silica spheres by hydrolytic cocondensation of 3-aminopropyltriethoxysilane and vinyltriethoxysilane," Langmuir, vol. 26, no. 2, pp. 730-735, 2010.

[26] P. L. Ritger and N. A. Peppas, "A simple equation for description of solute release II. Fickian and anomalous release from swellable devices," Journal of Controlled Release, vol. 5, no. 1, pp. 37-42, 1987. 

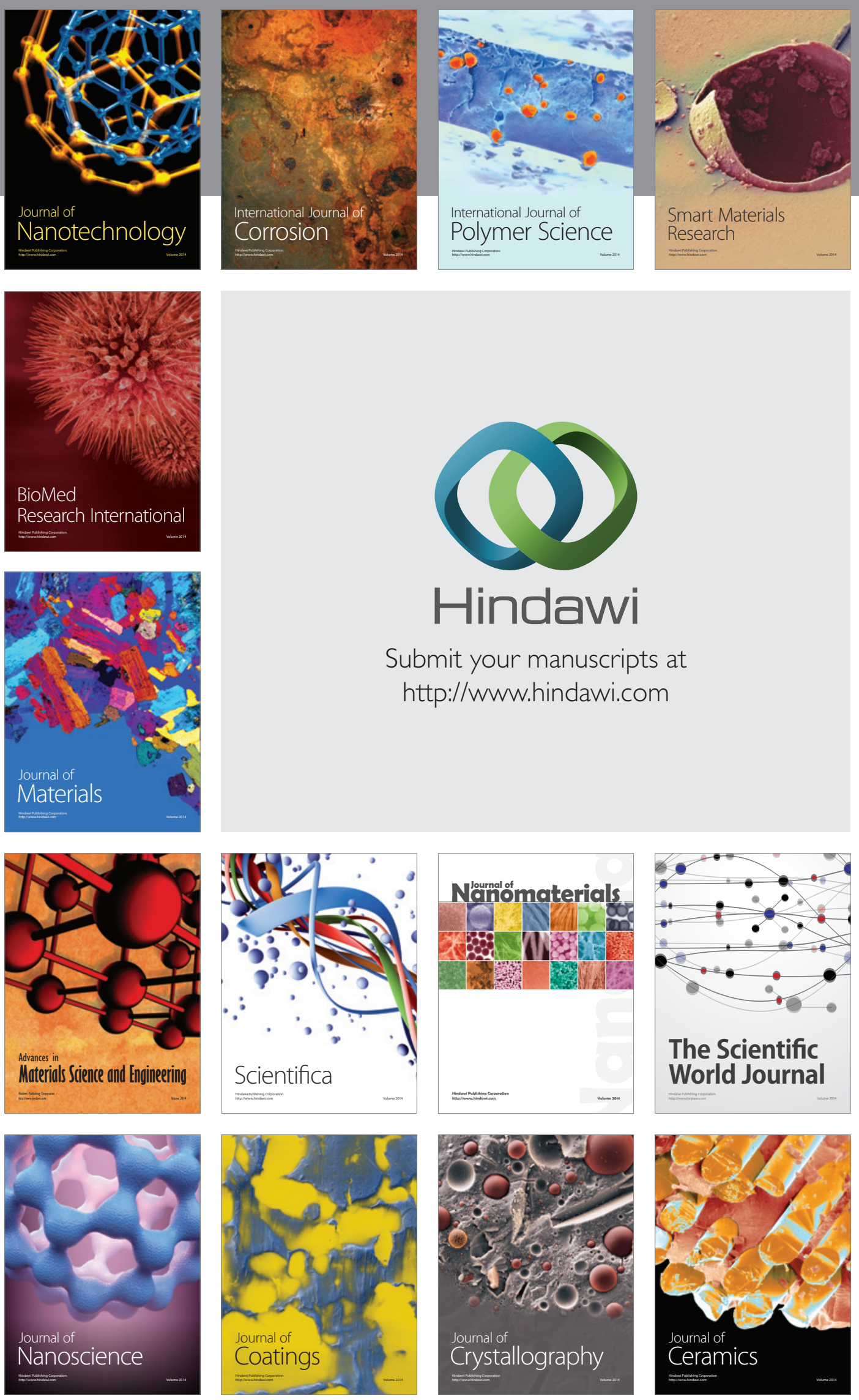

The Scientific World Journal

Submit your manuscripts at

http://www.hindawi.com

\section{World Journal}

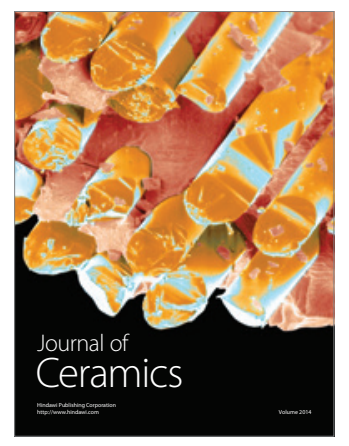

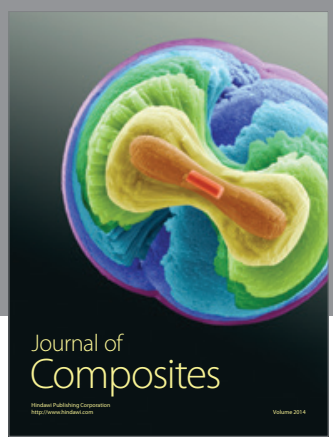
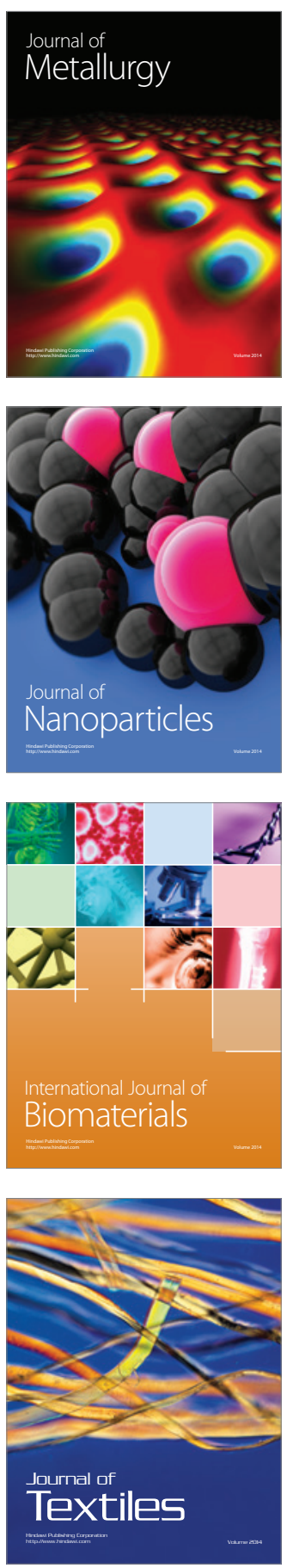